ص ص[ [

$$
\begin{aligned}
& \text { العلاقة السبية بين رأس المال الأجنبي والاستثمار المحلي } \\
& \text { في عينة مختارة من الدول الآسيولية الآنية }
\end{aligned}
$$

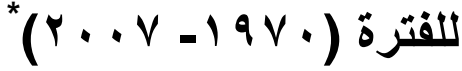

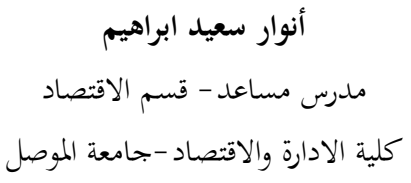

anwar_alnaqqar@yahoo.com

\author{
الدكتور مروان عبد المالك ذنون \\ مدرس - قسم الاقتصاد \\ كلية الادارة والاقتصاد -جامعة الموصل \\ marthano2001@yahoo.com
}

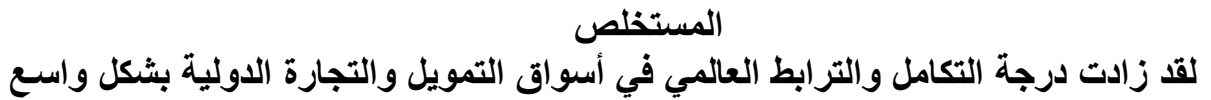

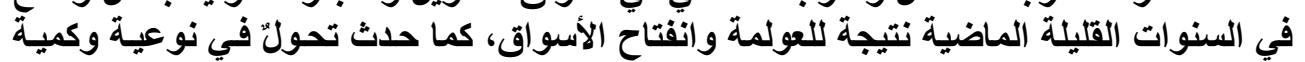

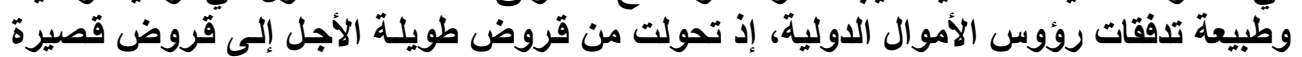

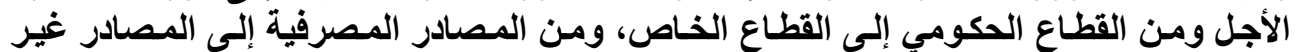

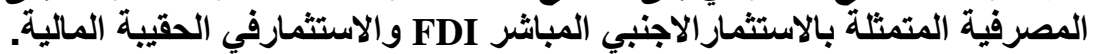

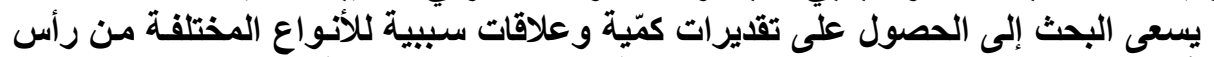

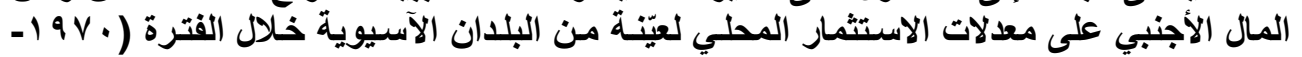

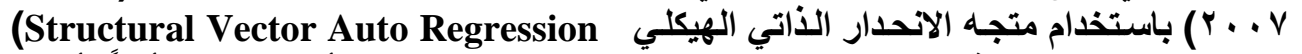

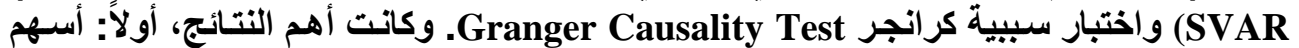

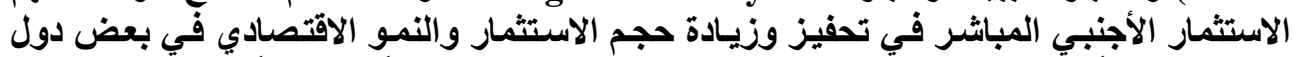

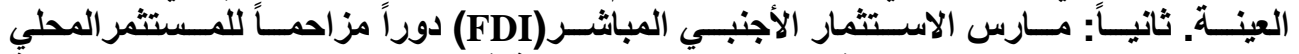
Crowding-out

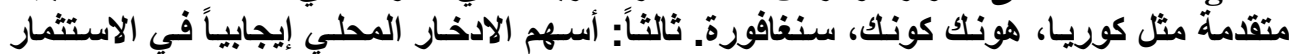

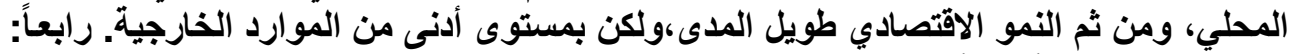

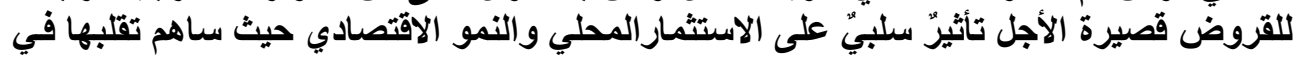

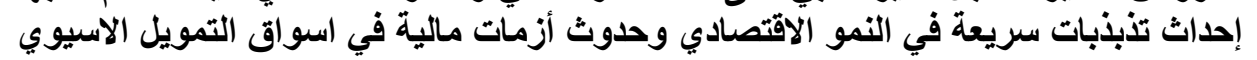

الكلمات المفتاحية: العلاقة السبيية، رأس المال الأجنبي، الاستثمار المحل.

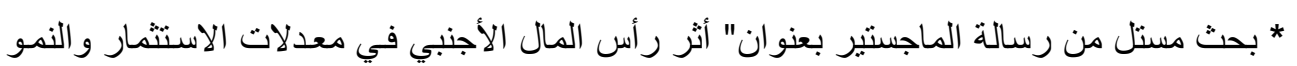

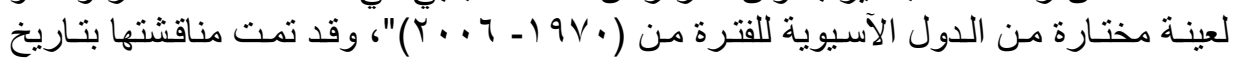
$. r \cdot 9 / 7 / 9$ 


\title{
The Granger Causality Relation between Foreign Capital and Domestic Investment for the Sample of the Asian Countries 1970-2007
}

\author{
Marwan A. Thanoon (PhD) \\ Lecturer \\ Department of Economics \\ University of Mosul
}

\author{
Anwar S. Ibraheem \\ Assistant Lecturer \\ Department of Economics \\ University of Mosul
}

\begin{abstract}
The degree of integration in the global financial markets has increased dramatically in recent years. Net capital flows to developing economics have reached the highest level since the 1980s debt crisis. The composition of international Capital flows to developing economics has also become more adverse in the last decade or so. There has been a shift from long-term loans mainly belong to governments, to short-term loans belong to private sector, and from bank to non-bank sources such as direct investment flows and portfolio investments. This main objective of this research is provides quantitative assessments of the effect of various types of the foreign capital flows on the Investment rate of a sample of Asian countries for the period (1970-2007). The empirical analysis was based on Structural Vector Auto Regression (SVAR) and Granger Causality test, and we found; first, the Foreign Direct Investment (FDI) has enhancing and increasing the domestic investment. Second, the domestic savings contribute positively to growth. Third, the short-term capital inflows (Hot Money) are more volatile and have adverse effect on the economic growth. The volatile of its rate had contributed strongly in created the crisis in Asian financial markets.
\end{abstract}

Key Words: Granger Causality, Foreign Capital, Domestic Investment

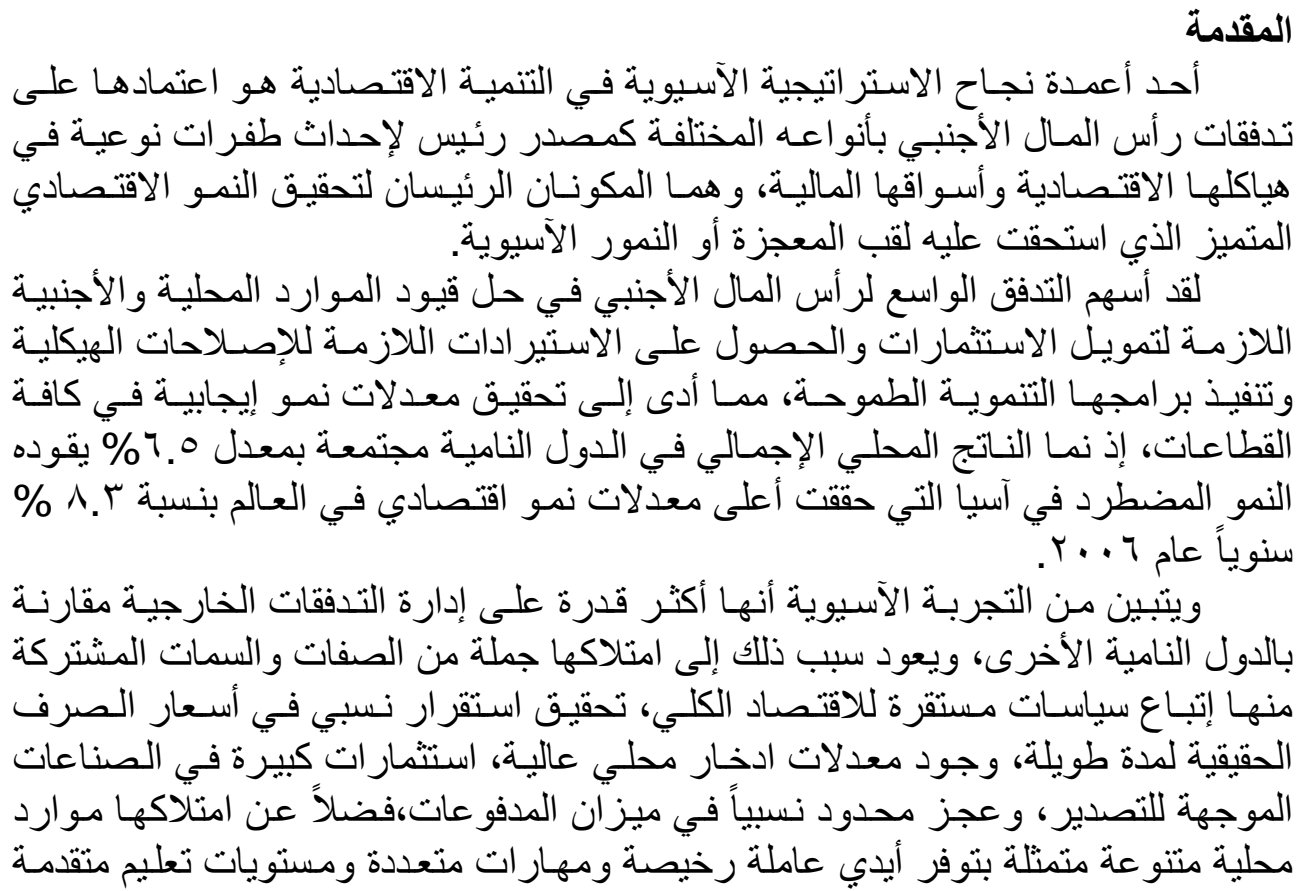


و إدارة كفـو وءة ير افقهـا اعتمـاد سياسـات اقتـــادية مرنــة تتكيـف سـريعاً مـع التطــور ات

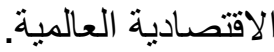

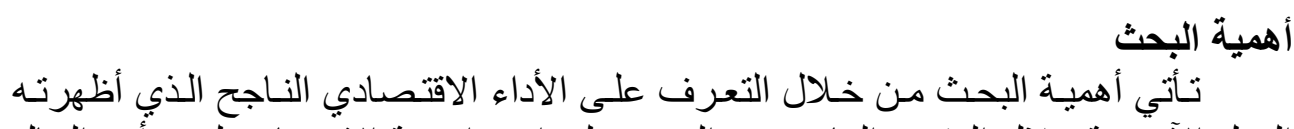

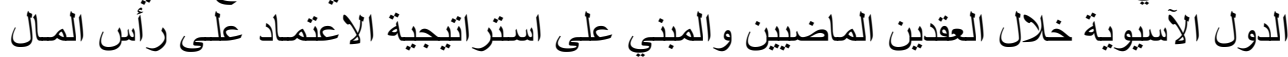

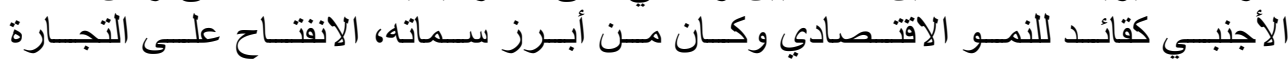

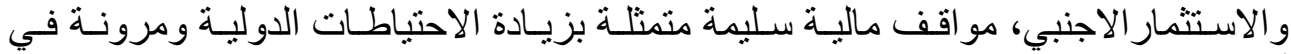

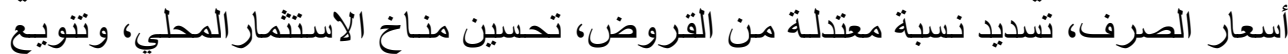

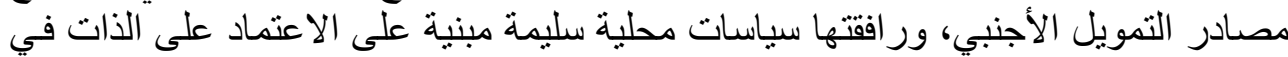

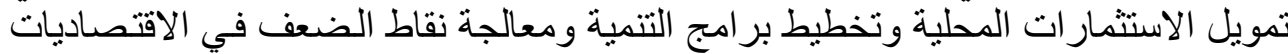

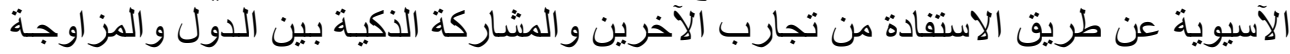

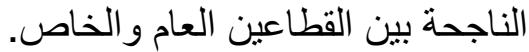

مشكلة البحث

تتمثل المشكلة الاساسية في أن الدول الاسبوية تواجها مصاعب في تعبئة الموارد

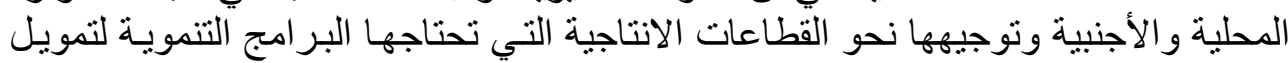

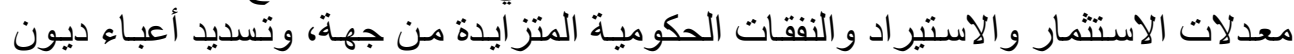
خارجية وداخلية منر اكمة لسنو اتل سابقة من جهة أخرى.

يهدف البحث إلى تقدير وتحليل أثر رأس المـال الأجنبي على معدلات الاستثمار

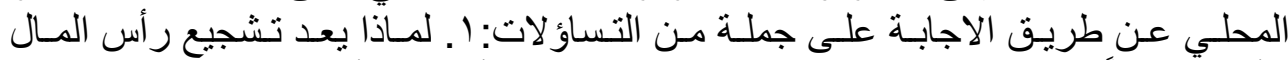

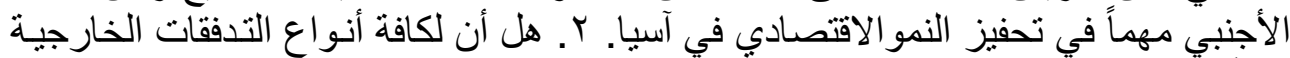

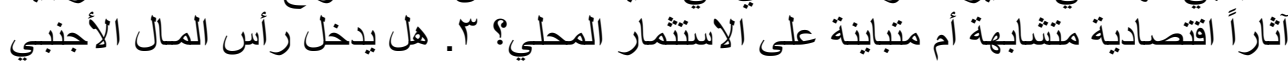

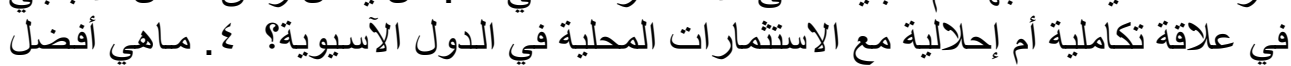

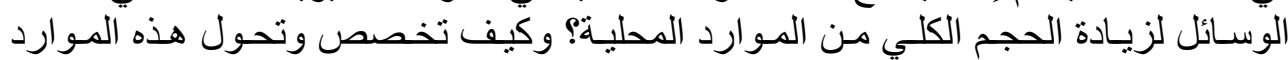
المحلية و الأجنبية إلى استثمار ات إنتاجية في قطاعات الاقتصاد المختلفة؟

يفترض البحث أن لتدفقات رأس المسال الأجنبي بغض النظر عن نوعها ومصدرها

\section{فرضية البحث}

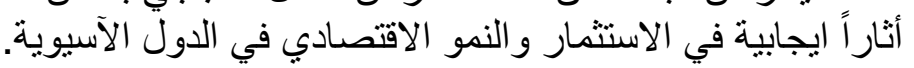

منهج البحث

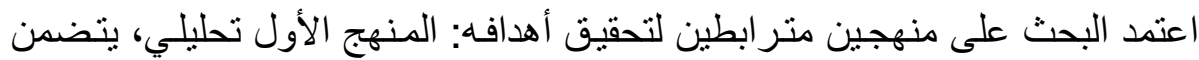

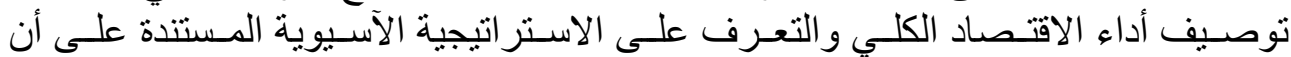

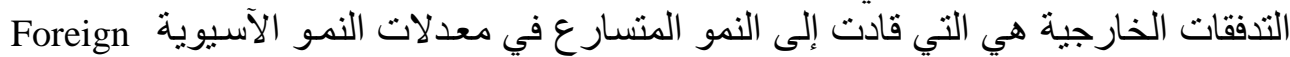

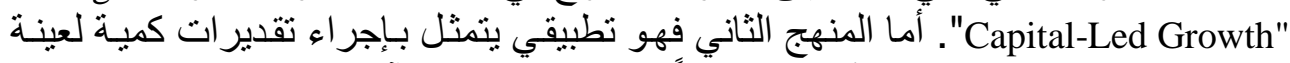

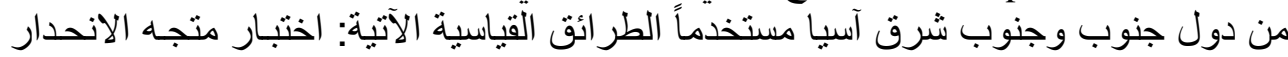

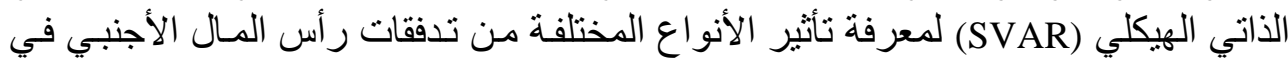




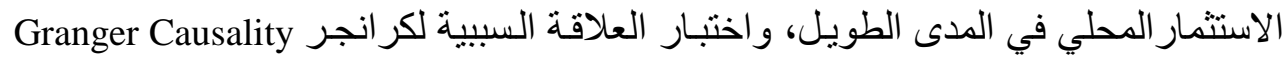

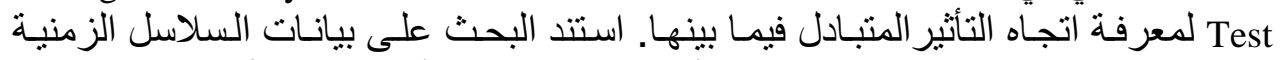

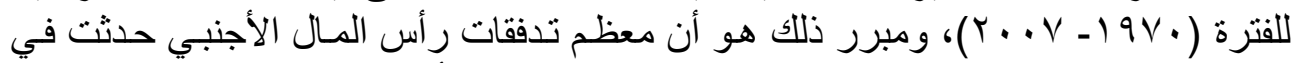

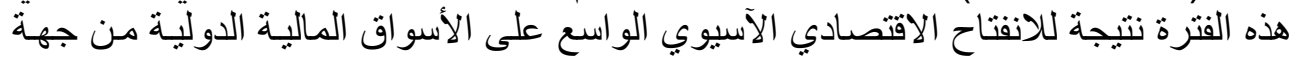

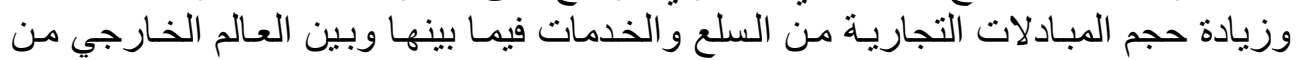

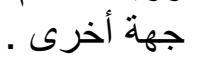

\section{ماهية رأس المال الأجنبي وأنواعه المختلفة}

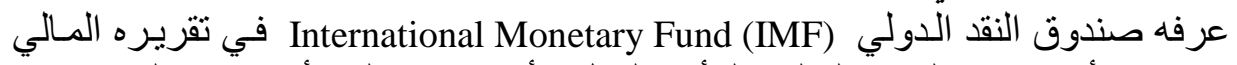

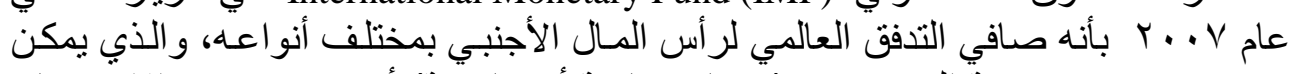

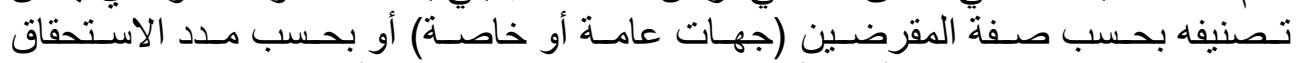

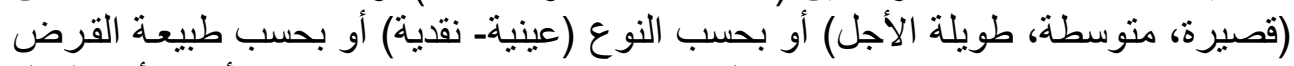

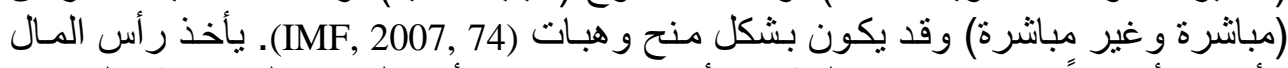

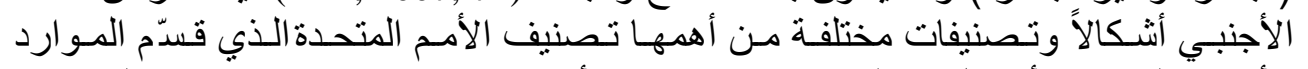

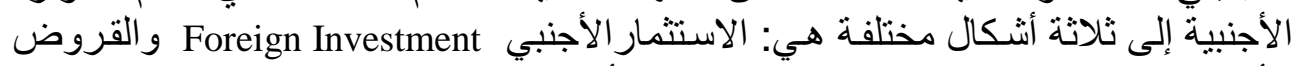

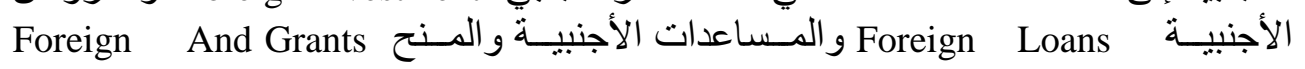
.Assistance حجم تدفقات رأس المال الأجنبي تثنير البيانات الرسمية التي تصدر ها التئي المنظمات الدولية مثل البنك و الصندوق الدولينين

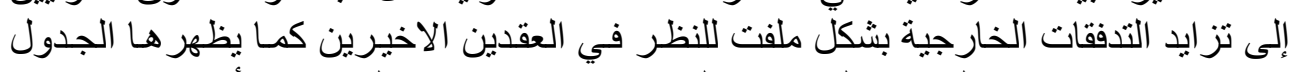

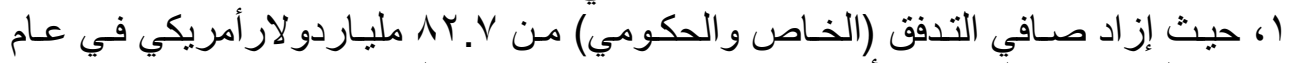

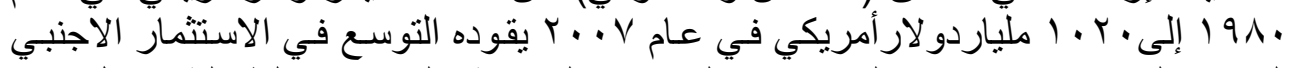

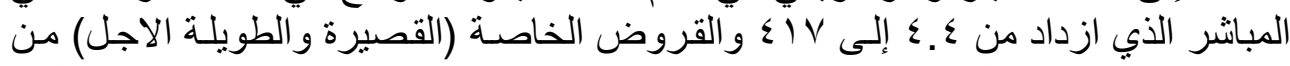

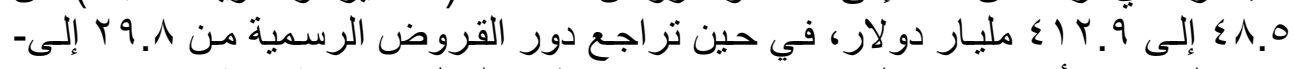

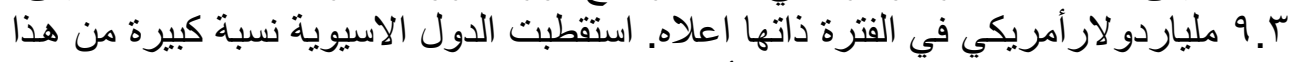

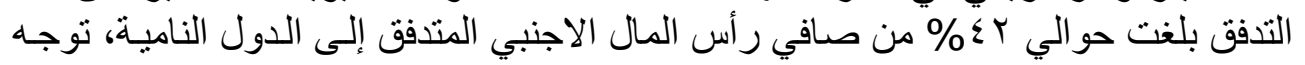

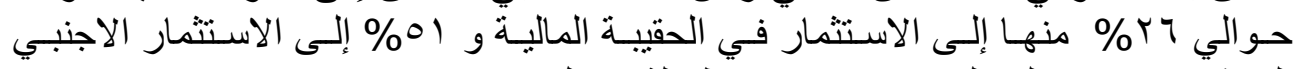

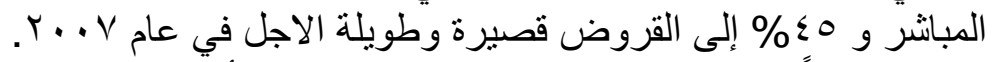

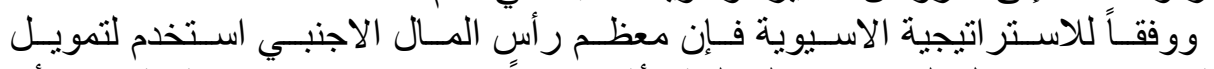

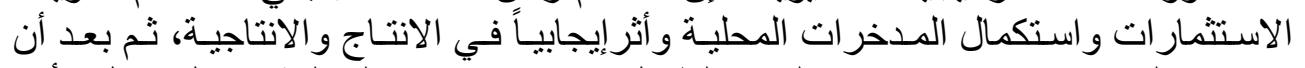

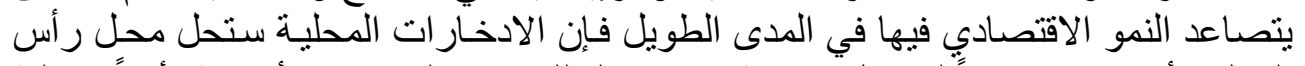

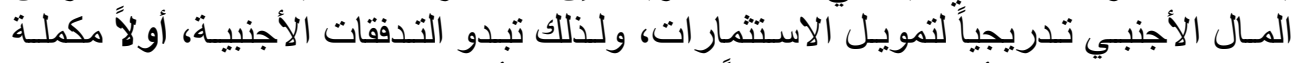

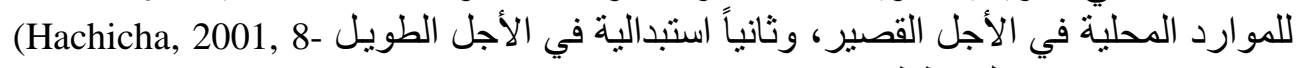
(10) 
ذنون وابراهيم]

$$
\begin{aligned}
& \text { تدفم كفايةالادخار ات المحلية }
\end{aligned}
$$

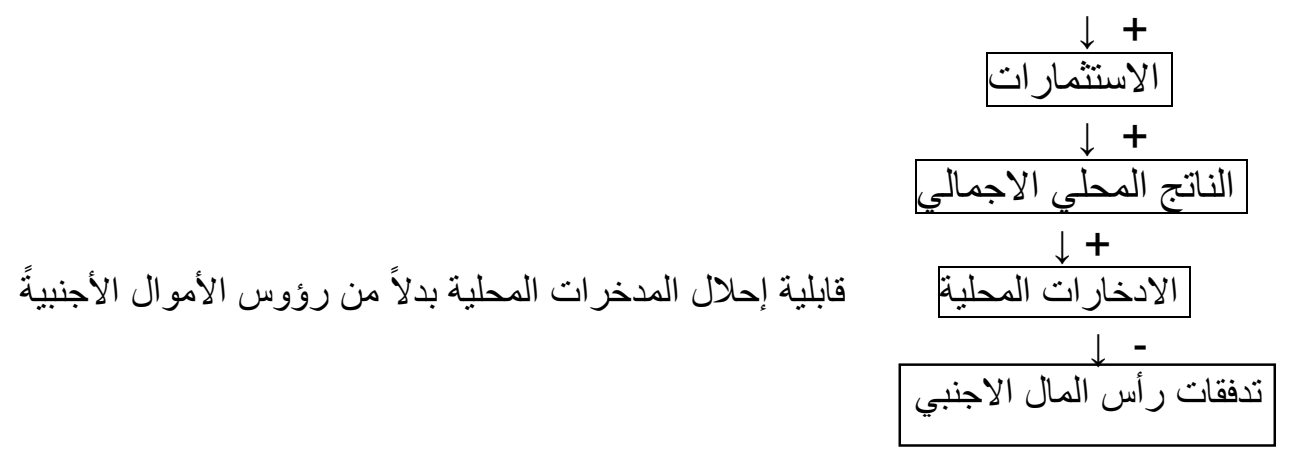

|لمخطط |

الاستراتيجية الاسيوية في استقطاب رأس المال الاجنبي

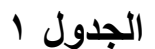

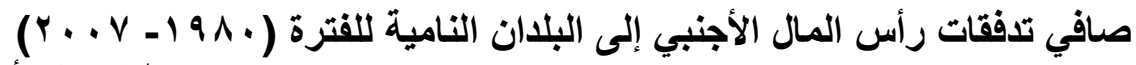
مليار دولار أمريكي

\begin{tabular}{|c|c|c|c|}
\hline$r \cdot v$ & $r \ldots$ & 191. & السنوات \\
\hline $1 \cdot r \cdot$ & $\mid \wedge 1$ & $\Lambda T . V$ & صافي التدفق (الخاص و الحكومي) \\
\hline 1.19 & $1 \wedge V_{.1}$ & or. 9 & صافي التدفق الخاص \\
\hline 717 & $1 \wedge$. & $\varepsilon . \varepsilon$ & ا - صافي تدفق الاستثمار ات \\
\hline$\varepsilon 1 V$ & 177.0 & $\varepsilon . \varepsilon$ & FDI \\
\hline $1 \leq 0$ & 1T. & $\because \cdot$ & PFI \\
\hline$\varepsilon . T . O V$ & $1 . r$ & $\vee \wedge . r$ & صافي تدفق القروض \\
\hline q. T- & $0.9-$ & rq.^ & القروض الرسمية \\
\hline$\varepsilon \mid r . \wedge V$ & V. 1 & $\varepsilon \wedge .0$ & القروض الخاصة \\
\hline t八T & IT. & r. & طويلة الأجل \\
\hline $1 \% q . \wedge V$ & $7 . \mu_{-}$ & 10.7 & قصيرة الأجل \\
\hline
\end{tabular}

Sources: International Monetary Fund (IMF), World Bank, and World Economic Outlook Databases, 2008 and other Years . 
تسعى الدول النامية من الاعتماد على تدفق رأس المال الأجنبي إلى تحقيق جملة من

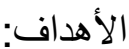

تسريع بناء الهياكل الارتكازية لتوفير الخدمات الأساسية للمشاريع الانتاجية لديها.

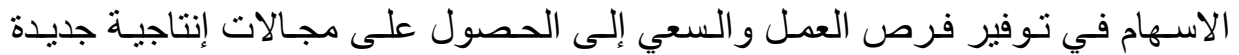
وتحسين استخدام الموارد الطبيعية وتخفيض ولفيلف الإلفي الانتاج.

ادخال المعدات التكنولوجيّة الحديثة وتطوير إنتاجية المنشآت القائمسة وتحسين مستويات أدائهاونو عية إنتاجها وقدر اتها التنافسية.

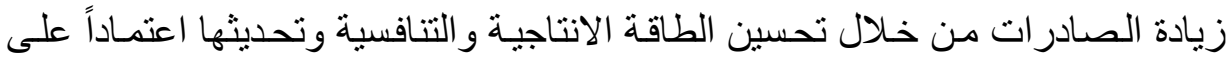

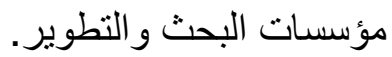
البحث عن أسواق عالمية جديدة لتسويق إنتاجها في الخارج. الحصول على فرص تدريب متقدمة. تنفيذ بر امج إدارية حديثة لإدارة المشاريع وتوزيع الموارد.

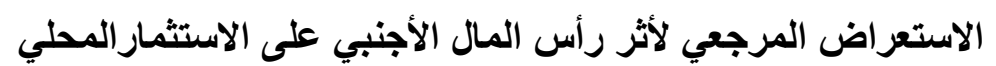

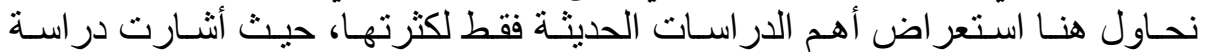

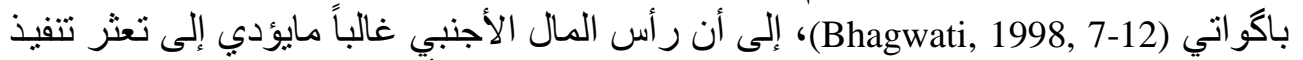

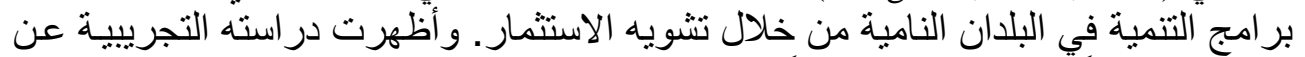

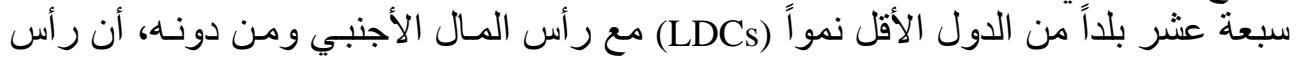

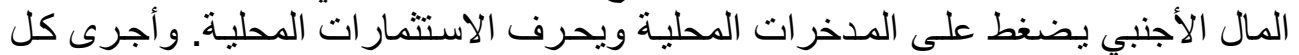

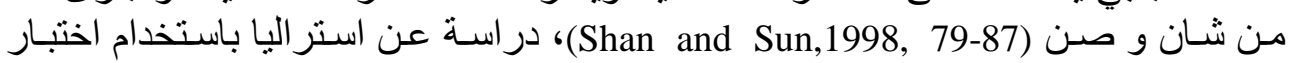

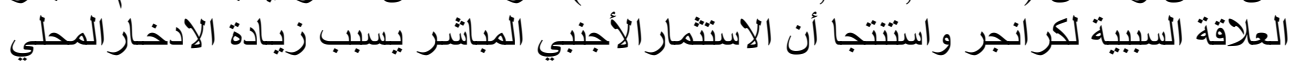

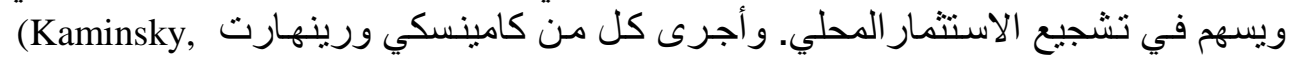
Reinhart, 1998, 444-448)

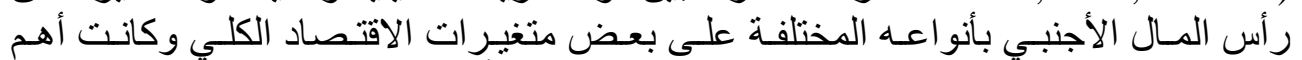

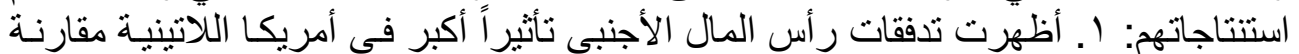

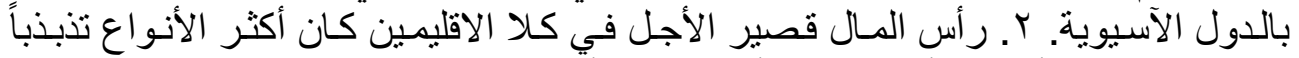
وسلبية مقارنة بالأنواع الأخرى من رأس المال المبر الأجنبي.

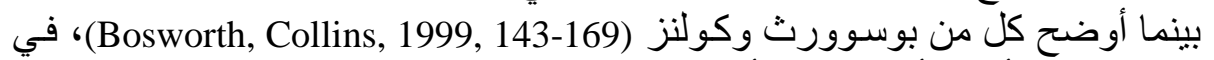

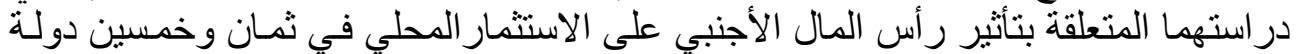

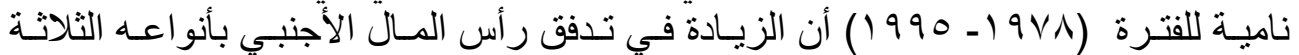

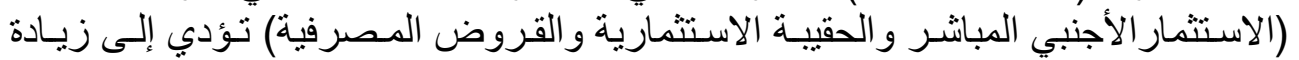

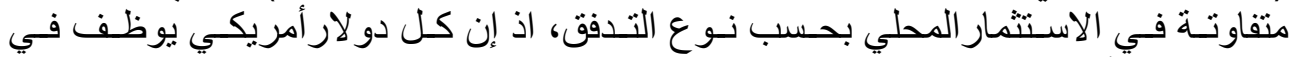

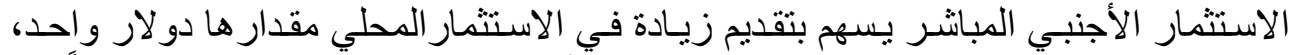

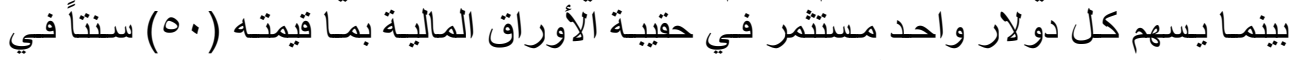

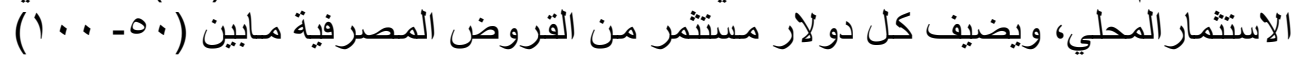

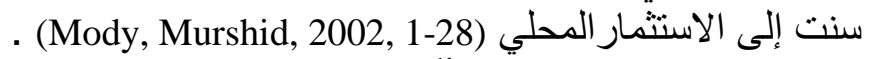

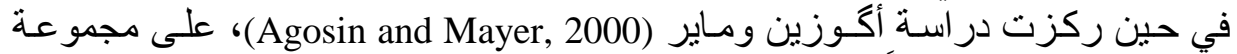

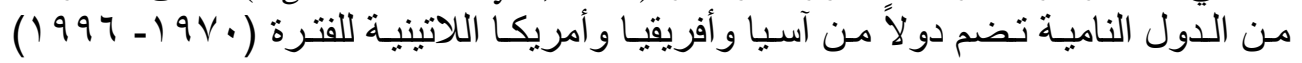




\section{ذنون وابراهيم]}

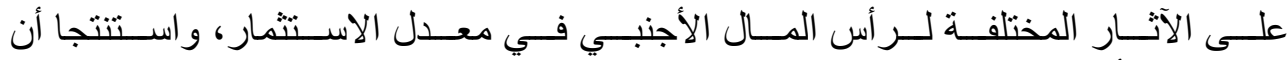

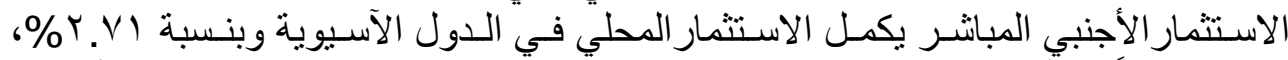

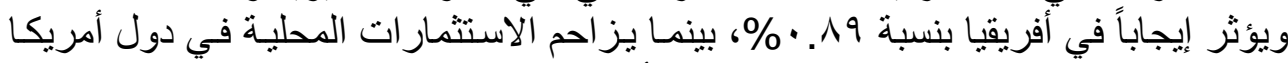

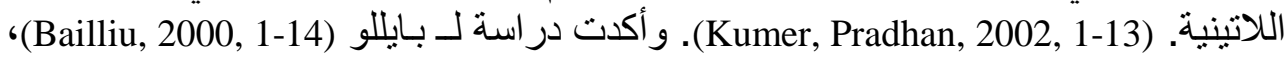

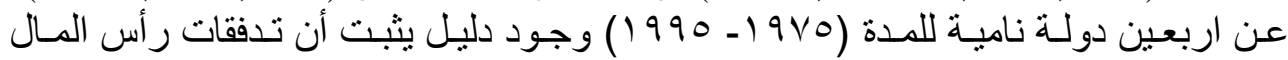

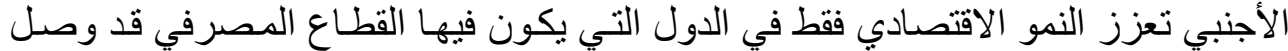

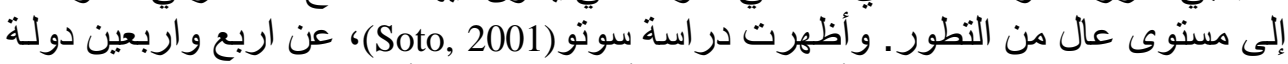

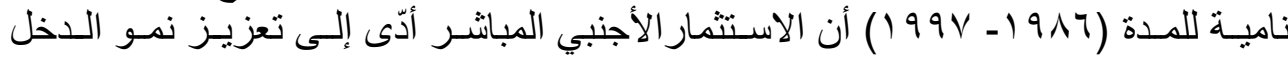

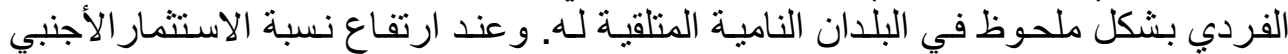

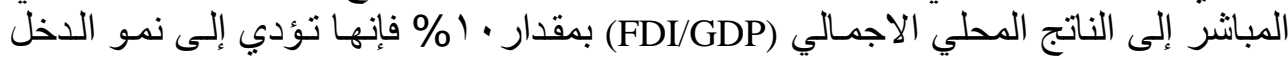

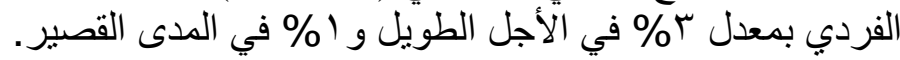

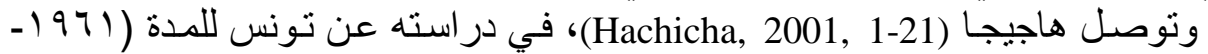

إلى وجود (باستخدام اختبار التناظر المشترك لجوهانسن (Johanson`s ConitegrationTtest)

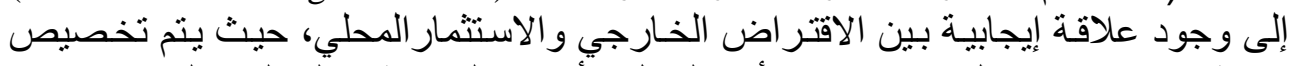

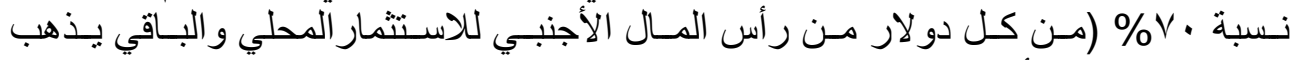

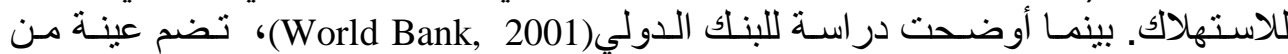

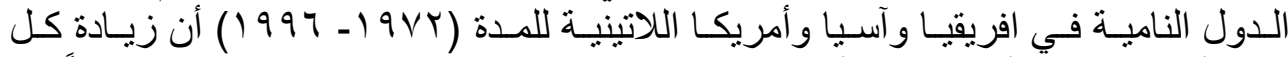

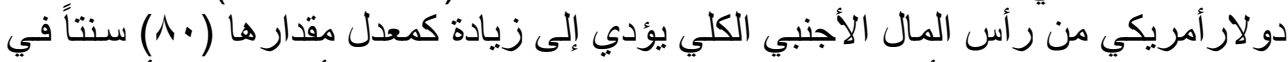

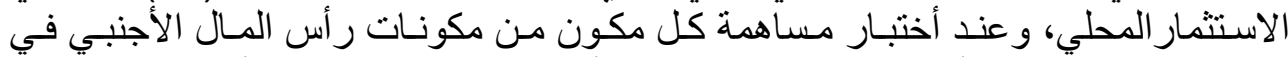

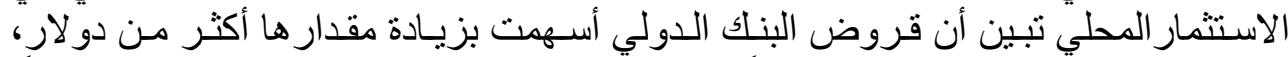

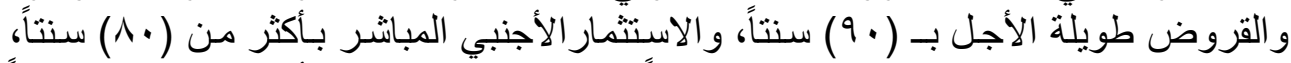

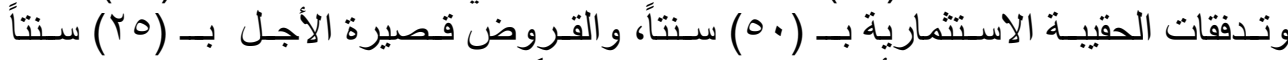

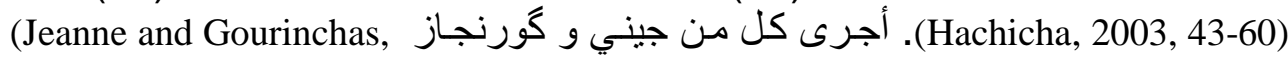
(2006، دراستين، تناولت الأولى أهمية التمويل الذاتي في الدول النامية في فترة التسعينات،

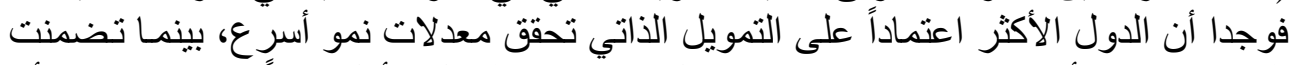

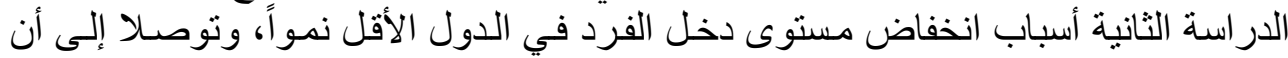

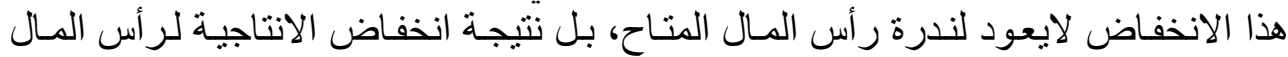

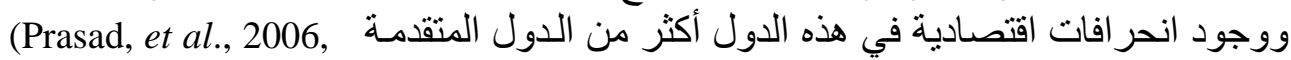

نستنتج مها تقدم أن هناك تبايناً واضحاً في تأثير الأنواع الذختلفة من رأس المال

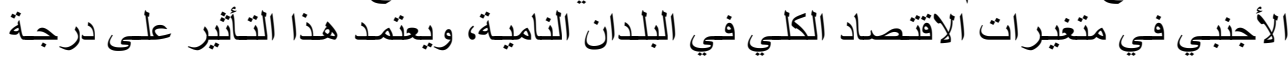

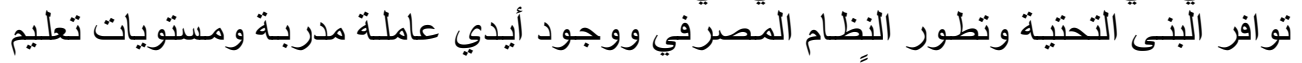
متقدمة ووضوح القو انين فضلاً عن الاستقرار السياسي.

\footnotetext{
الاختبارات المستخدمة في البحث

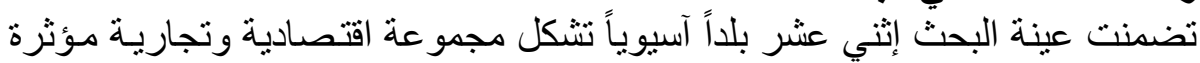

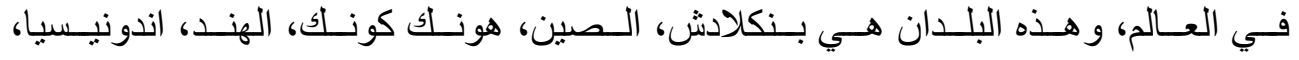




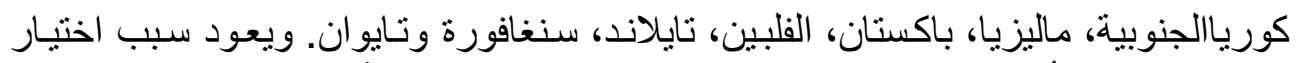

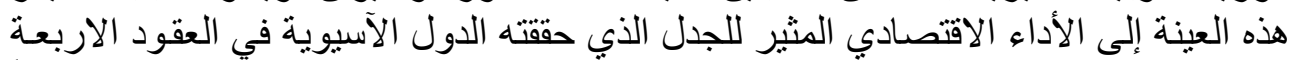

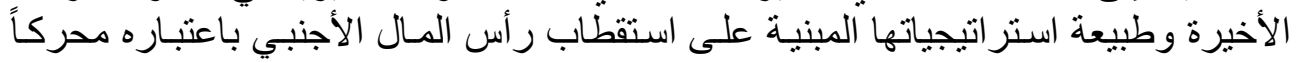
لنمو الاقتصاد الآسيوي.

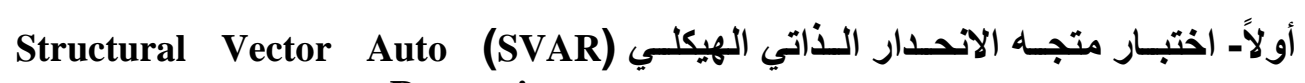
Regression

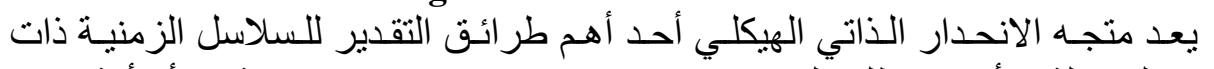

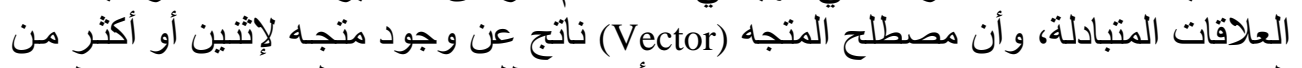

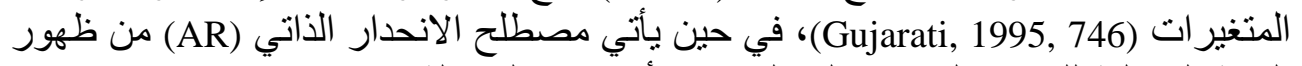
القيمة المتخلفة للمتغير المعتمد على الجانب الأيمن من المعادلة:

$$
\mathrm{I}_{\mathrm{it}}=\alpha_{\mathrm{o}}+\beta_{1} \mathrm{I}_{\mathrm{it}-\mathrm{n}}+\beta_{2} \sum \mathrm{X}_{\mathrm{it}-\mathrm{n}}+\mu_{\mathrm{t}}
$$

اذ إن: Iit تمثل المتغير المعتمد نسبة الاستثمار المحلي/ IDP

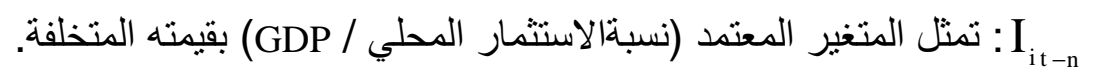

: SX $X_{\text {it-n }}$

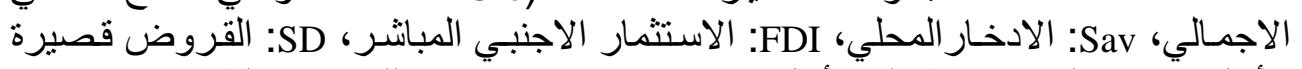

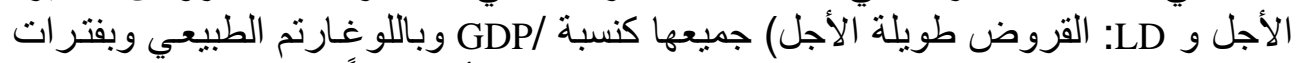

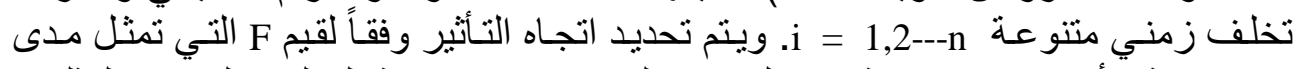

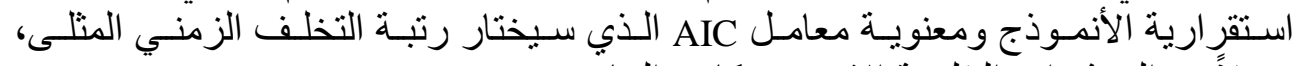
فضلاً عن المؤشرات التقليدية الاخرى وكانت النتائج: 
ذنون وابراهيم

\begin{tabular}{|c|c|c|c|c|c|c|c|c|c|}
\hline & Gro & SAV & FDI & SD & LD & $\mathbf{R}^{2}$ & $\mathbf{R}^{2} \mathbf{A d j}$ & $\mathbf{F}$ & $\begin{array}{l}* * * * \\
\text { AIC }\end{array}$ \\
\hline بنكلادش & $\begin{array}{l}-0.03 \\
-4.4^{*}\end{array}$ & $\begin{array}{l}-0.18 \\
-4.6^{*}\end{array}$ & $\begin{array}{c}0.03 \\
1.7^{* *}\end{array}$ & $\begin{array}{c}0.06 \\
1.54 * *\end{array}$ & $\begin{array}{c}0.17 \\
3.00^{*}\end{array}$ & $\begin{array}{c}\% 9 \\
8\end{array}$ & $\% 97$ & 100 & 5.52 \\
\hline الصين & $\begin{array}{l}0.02 \\
4.0^{*}\end{array}$ & $\begin{array}{c}0.4 \\
1.9^{*}\end{array}$ & $\begin{array}{l}0.02 \\
0.33\end{array}$ & $\begin{array}{c}0.02 \\
1.4^{* *}\end{array}$ & $\begin{array}{l}0.01 \\
0.85\end{array}$ & $\begin{array}{l}93 \\
\%\end{array}$ & $\% 85$ & 11 & $\begin{array}{c}15.8 \\
4\end{array}$ \\
\hline هونك كونك & $\begin{array}{l}0.01 \\
1.15\end{array}$ & $\begin{array}{c}0.69 \\
1.39 * *\end{array}$ & $\begin{array}{c}-0.001 \\
-0.24\end{array}$ & $\begin{array}{l}0.05 \\
1.05\end{array}$ & $\begin{array}{l}0.22 \\
2.5^{*}\end{array}$ & $\begin{array}{l}87 \\
\%\end{array}$ & $\% 75$ & 7.2 & $7 . .91$ \\
\hline اندونيسيا & $\begin{array}{l}0.04 \\
5.7^{*}\end{array}$ & $\begin{array}{c}0.33 \\
1.48^{* *}\end{array}$ & $\begin{array}{c}-0.001 \\
-0.16\end{array}$ & $\begin{array}{c}0.28 \\
1.31 * *\end{array}$ & $\begin{array}{c}-0.61 \\
- \\
1.7 * *\end{array}$ & $\begin{array}{c}\% 8 \\
7\end{array}$ & $\% 80$ & 12.9 & 5.34 \\
\hline الهند & $\begin{array}{l}0.03 \\
3.7^{*}\end{array}$ & $\begin{array}{c}1.52 \\
2.97 *\end{array}$ & $\begin{array}{c}0.017 \\
1.30\end{array}$ & $\begin{array}{l}0.03 \\
0.36\end{array}$ & $\begin{array}{l}0.04 \\
0.32\end{array}$ & $\begin{array}{l}83 \\
\%\end{array}$ & $\% 75$ & 9.6 & 3.59 \\
\hline كوريا & $\begin{array}{c}0.004 \\
0.71\end{array}$ & $\begin{array}{l}0.64 \\
4.6^{*}\end{array}$ & $\begin{array}{l}-0.005 \\
-1.127\end{array}$ & $\begin{array}{c}0.08 \\
1.5^{* *}\end{array}$ & $\begin{array}{l}0.04 \\
0.32\end{array}$ & $\begin{array}{l}86 \\
\%\end{array}$ & $\% 79$ & 11.4 & 5.44 \\
\hline ماليزيا & $\begin{array}{l}0.03 \\
1.21\end{array}$ & $\begin{array}{c}-0.65 \\
-1.97 *\end{array}$ & $\begin{array}{l}0.04 \\
0.41\end{array}$ & $\begin{array}{l}0.09 \\
0.69\end{array}$ & $\begin{array}{l}0.04 \\
0.16\end{array}$ & $\begin{array}{l}72 \\
\%\end{array}$ & $\% 57$ & 4.8 & 3.38 \\
\hline باكستان & $\begin{array}{l}0.03 \\
3.0^{*}\end{array}$ & $\begin{array}{c}0.002 \\
0.02\end{array}$ & $\begin{array}{c}0.9 \\
1.9^{*}\end{array}$ & $\begin{array}{c}0.4 \\
0.78\end{array}$ & $\begin{array}{l}0.35 \\
1.16\end{array}$ & $\begin{array}{l}65 \\
\%\end{array}$ & $\% 45$ & 3.4 & 2.5 \\
\hline الفلبين & $\begin{array}{c}0.03 \\
3.14^{*}\end{array}$ & $\begin{array}{l}0.07 \\
0.31\end{array}$ & $\begin{array}{l}-0.01 \\
-0.46\end{array}$ & $\begin{array}{l}0.01 \\
0.35\end{array}$ & $\begin{array}{c}0.03 \\
1.4^{* *}\end{array}$ & $\begin{array}{l}83 \\
\%\end{array}$ & $\% 74$ & 9.4 & 6.21 \\
\hline سنغافورة & $\begin{array}{l}0.007 \\
2.36^{*}\end{array}$ & $\begin{array}{c}0.34 \\
1.7 * *\end{array}$ & $\begin{array}{c}0.03 \\
1.0\end{array}$ & $\begin{array}{c}0.14 \\
2.19^{*}\end{array}$ & $\begin{array}{c}0.13 \\
2.24 *\end{array}$ & $\begin{array}{l}95 \\
\%\end{array}$ & $\% 92$ & 35 & 5.09 \\
\hline تايلاند & $\begin{array}{c}0.02 \\
2.44^{*}\end{array}$ & $\begin{array}{l}-0.24 \\
-0.67\end{array}$ & $\begin{array}{c}0.09 \\
1.7^{* *}\end{array}$ & $\begin{array}{l}0.12 \\
1.9 *\end{array}$ & $\begin{array}{l}0.25 \\
0.88\end{array}$ & $\begin{array}{l}84 \\
\%\end{array}$ & $\% 76$ & 10 & 2.6 \\
\hline تايوان & $\begin{array}{l}0.05 \\
2.3^{*}\end{array}$ & $\begin{array}{c}-0.76 \\
-1.95^{*}\end{array}$ & $\begin{array}{c}-0.03 \\
-2.87 *\end{array}$ & $\begin{array}{c}0.13 \\
1.7^{* *}\end{array}$ & $\begin{array}{l}0.32 \\
2.7 *\end{array}$ & $\begin{array}{l}79 \\
\%\end{array}$ & $\% 58$ & 3.85 & 5.1 \\
\hline
\end{tabular}

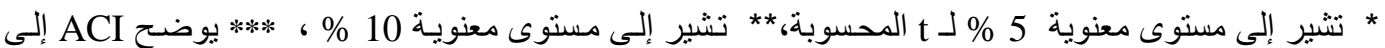

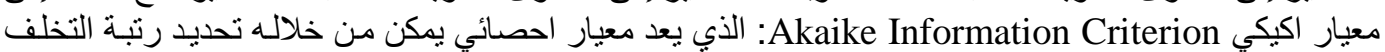

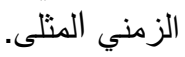

ويظهر من الجدول جملة من المؤشرات المشتركة

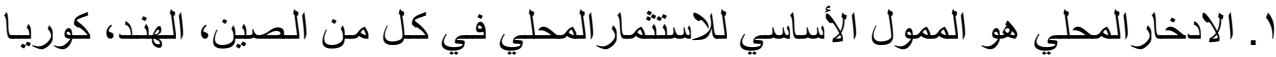

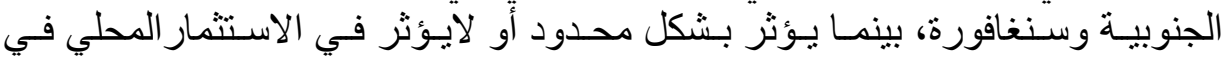

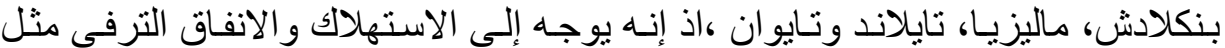

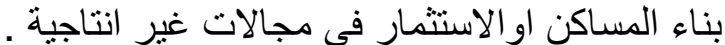

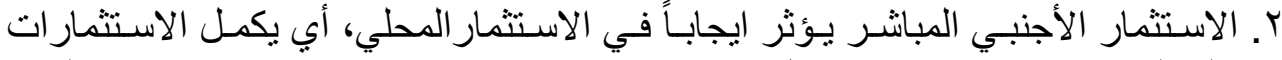

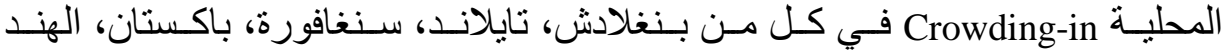

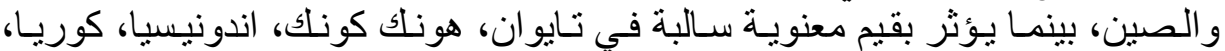

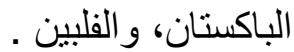




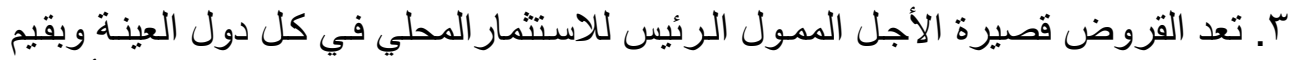

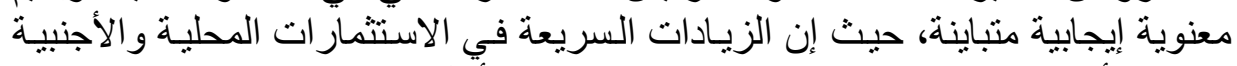

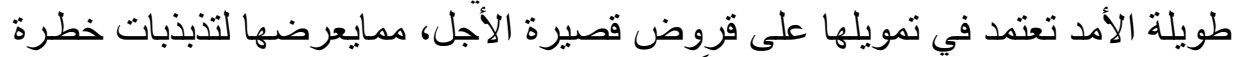

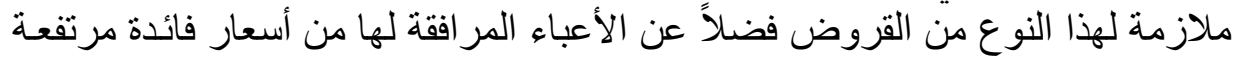

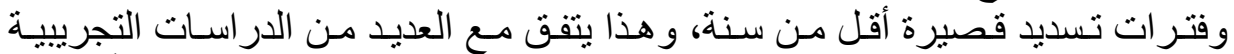

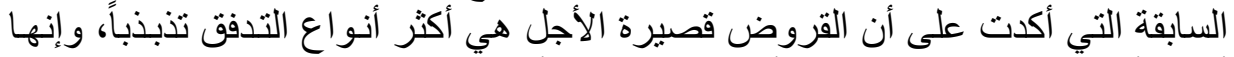

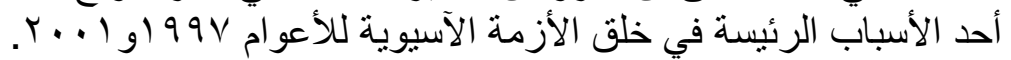

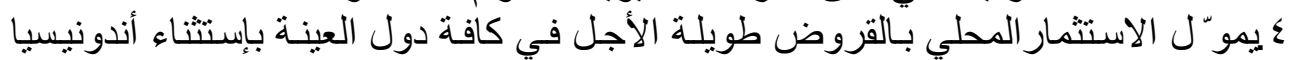

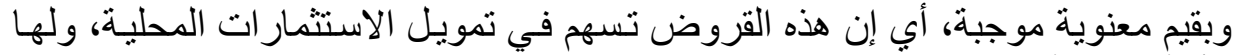

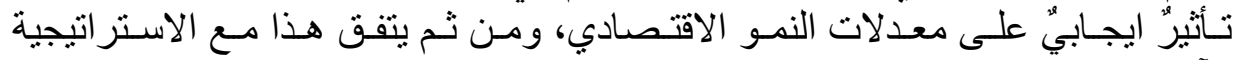

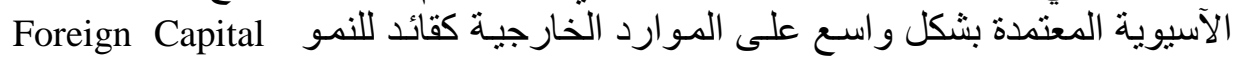
.Led Growth

\section{ثانياً- إختبار العلاقة السببية لكرانجر}

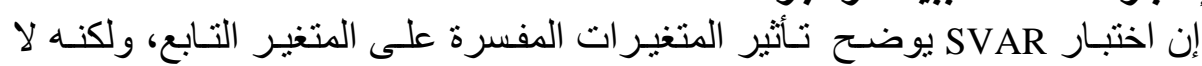

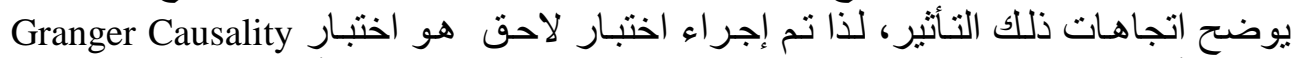

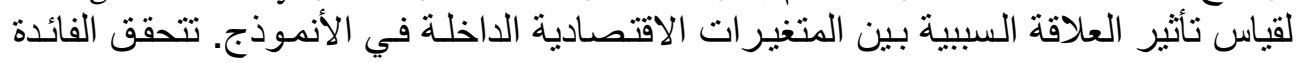

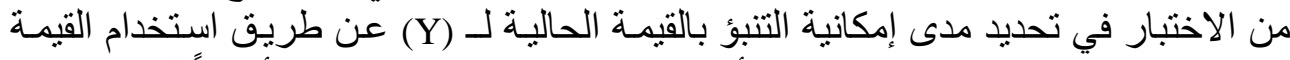

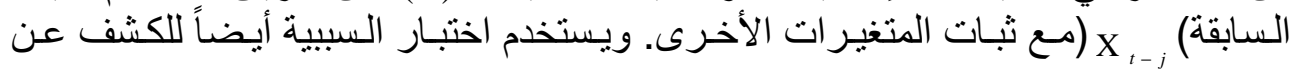

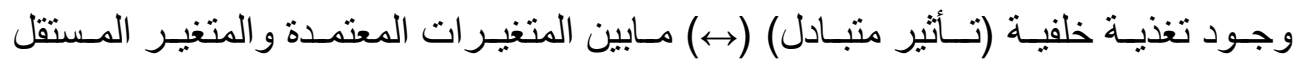

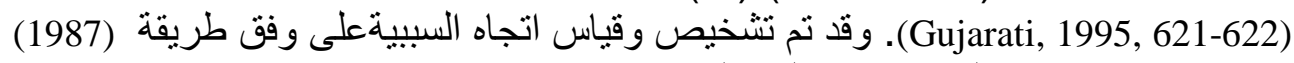
Granger and Engle

$$
\begin{array}{rc}
\Delta I_{t}=\Phi_{0}+\sum_{j=1}^{r} \Phi_{1 j} \Delta I_{t-j}+\sum_{j=0}^{r} \Phi_{2 j} \Delta X_{t-i_{r r}}+\mu_{t} & \cdots . .(\text { (') } \\
\Delta X_{t}=\eta_{0}+\sum_{j=1}^{s} \eta_{i j} \Delta I_{t-j}+\sum_{i=0}^{s} \eta_{2 j} \Delta X_{t-i_{s}}+v_{t}
\end{array}
$$

حيث Xirst تمثل المتغير ات المفسرة كنسبة من GDP وبصيغة الاختلافات الأولية

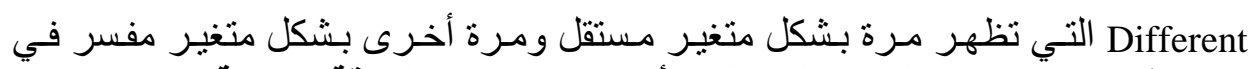

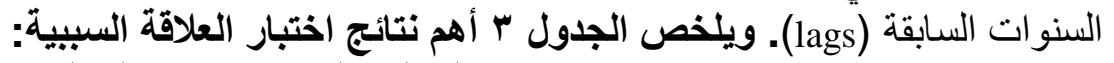

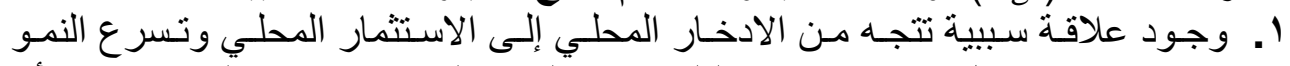

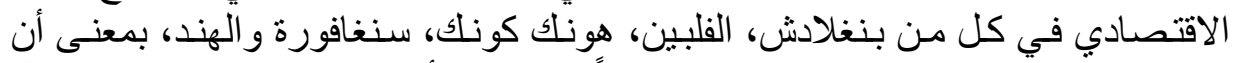

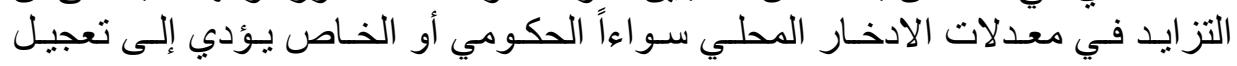

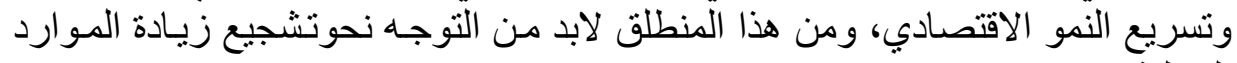
المحلية.

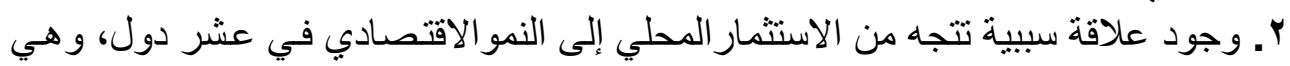

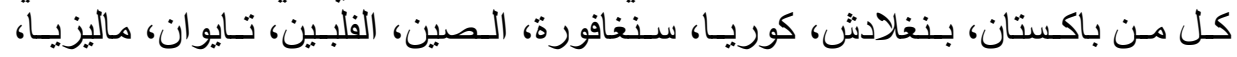

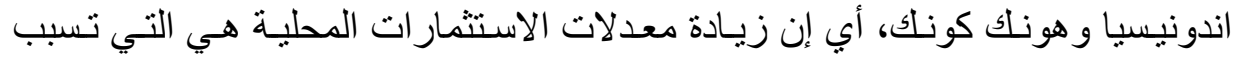




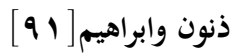

النمو الاقتصادي. و على واضعي السياسة الاقتصادية في الدول الآسيوية إعتماد سياسات

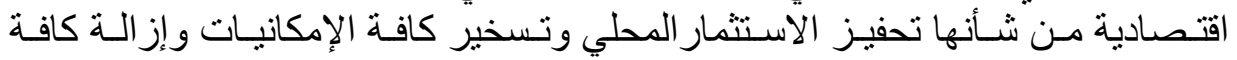

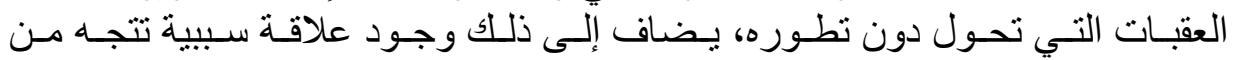

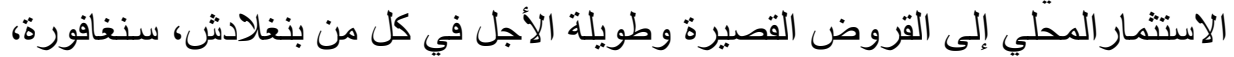
اندونيسيا، ماليزيا والفلبين، أي إن الاستثمار ات المحلية تعتمد عليها بشكل أساسي في سلغي

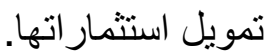

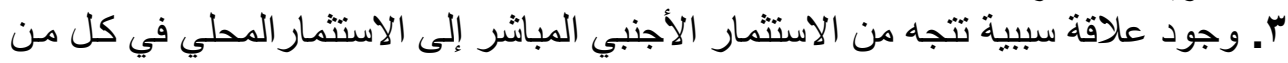

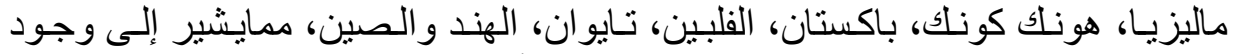

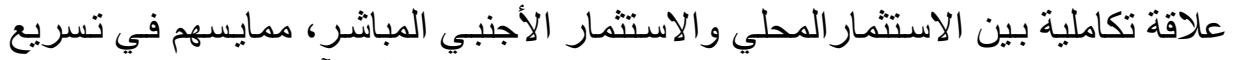

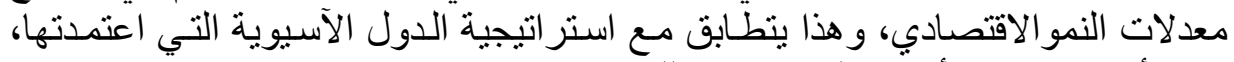

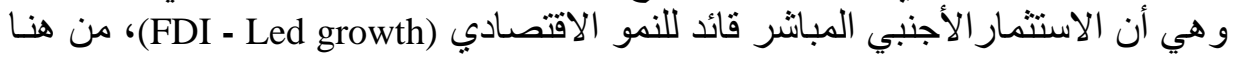

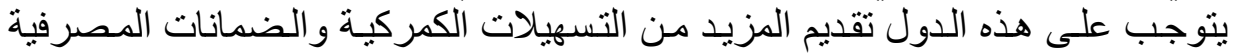

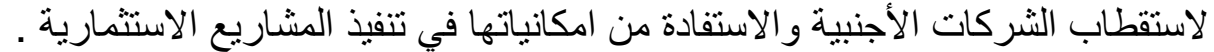

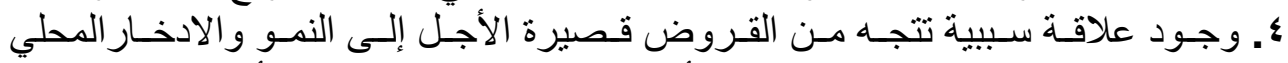

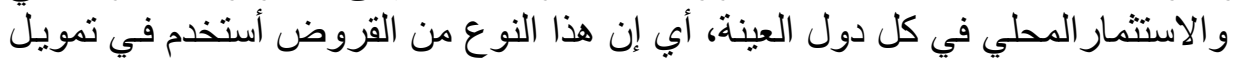

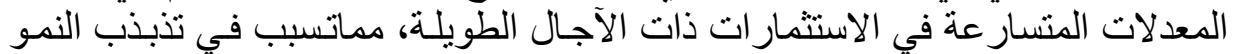

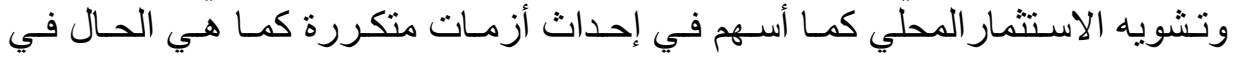

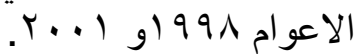

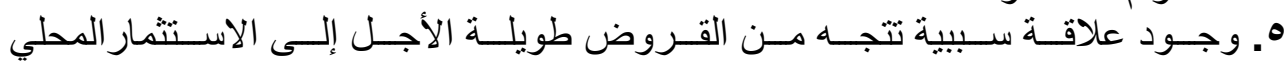

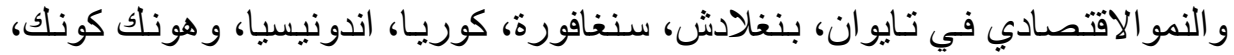

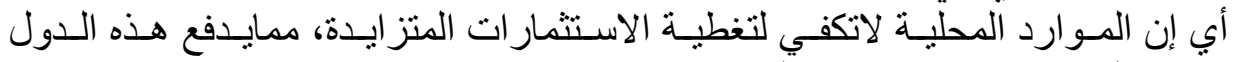
لإنستكمال مواردها بالاقتر اض آلخارجي. 


\begin{tabular}{|c|c|c|c|c|c|}
\hline قروض طويلة & قروض قصيرة & الأستثمار الأجنبي & الأنخار & النمو & الأتجاه \\
\hline كوريا الجنوبية، & الفلبين، باكستان، الفيلاند، & كونك ، كوريا سنغافورة هونك، & 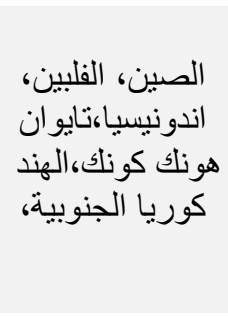 & 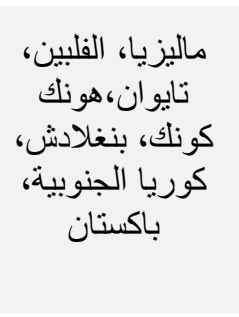 & 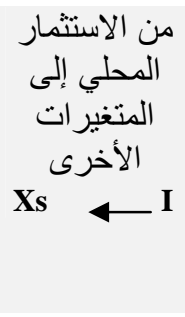 \\
\hline سنغنافورة، الفلبيا، ماليزيا، & 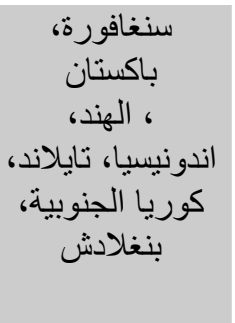 & سنغافورة الصين، & 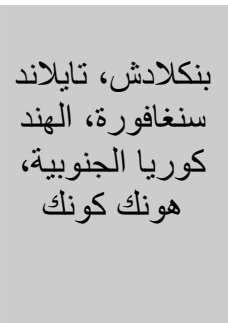 & 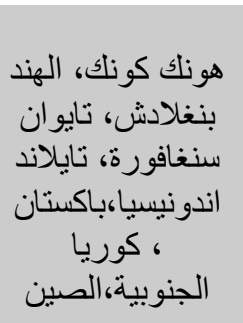 & 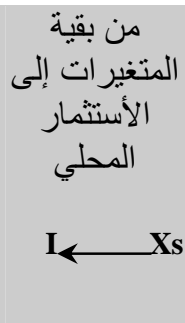 \\
\hline ماليزيا، بنغلادش كونك & باكستان ،تايلاند، & 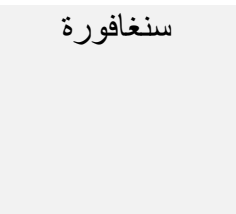 & هونك كونلك، الهندي & 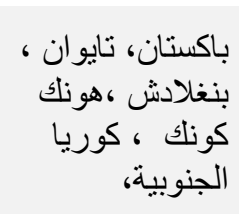 & 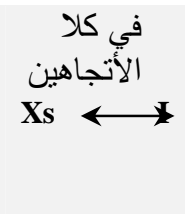 \\
\hline & & \multicolumn{4}{|c|}{ * تم استخدام برنامج "ج " EVIEW في اجر اء الاختبار ات اعلاه. } \\
\hline
\end{tabular}

\section{ا اهم الاستنتاجات}

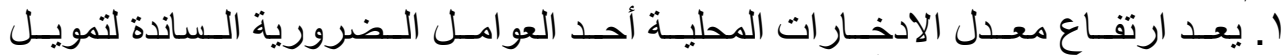

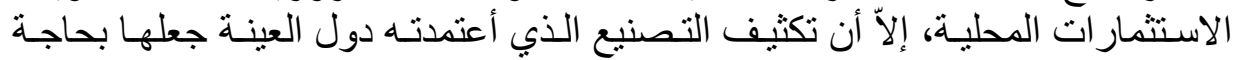

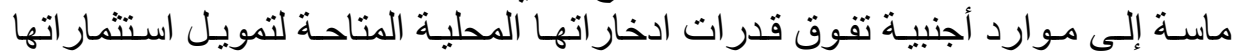

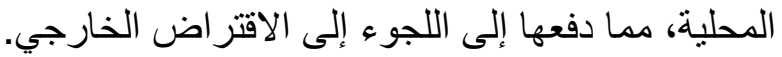

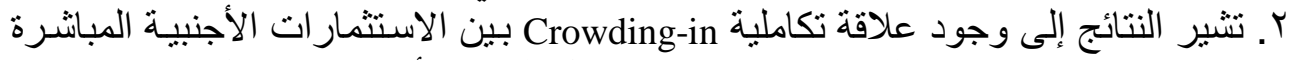

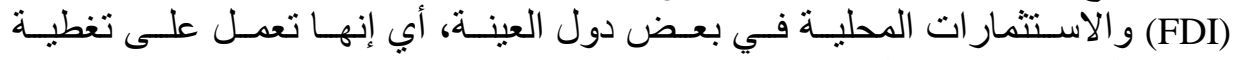

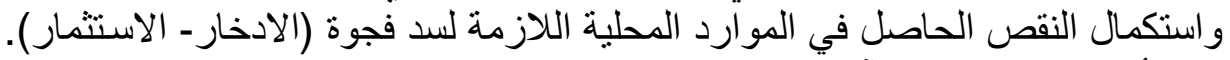
بينما أظهرت في القسم الآخر وجود علاقة تنافسية Crowding-out بينها.

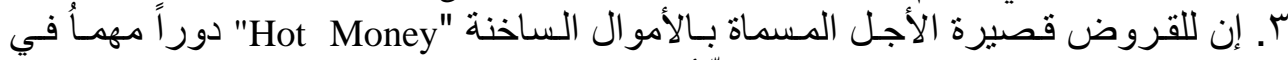

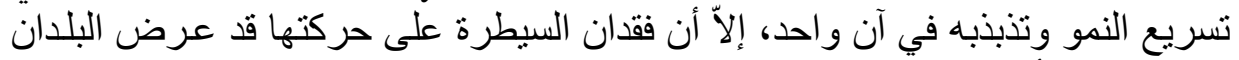

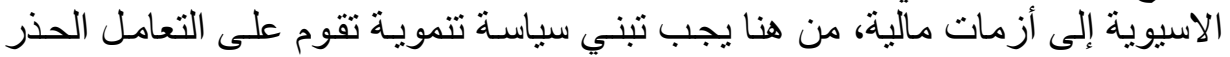
و المشروط مع هذا النوع من التدفقات من أجل الحد من الندالن الأزمات الاقتصادية.

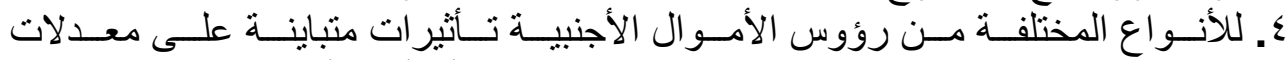

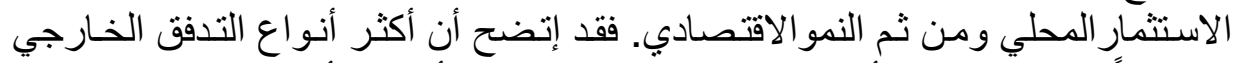

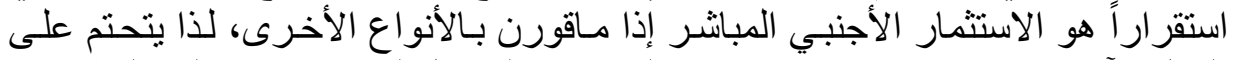

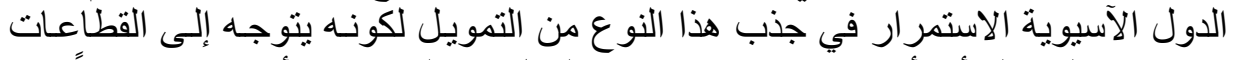

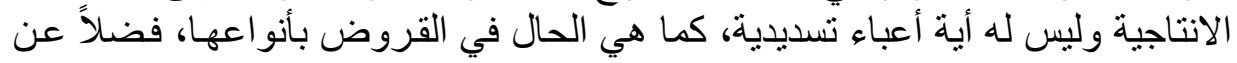




\section{ذنون وابراهيم [ ج]}

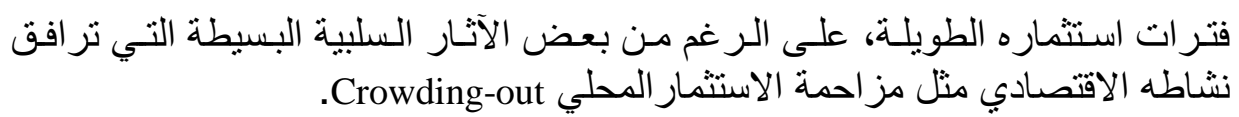

أهم المقترحات

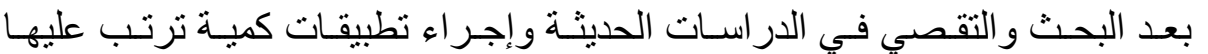

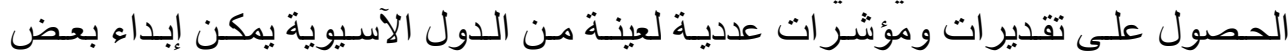

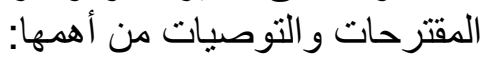

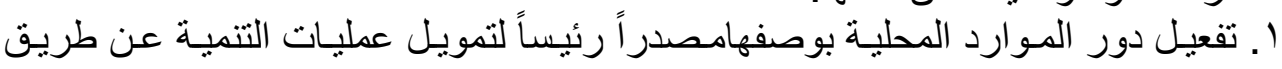

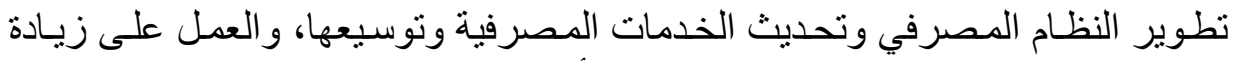

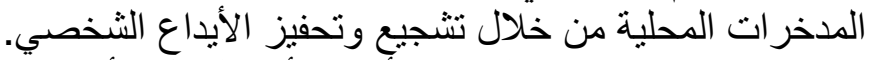

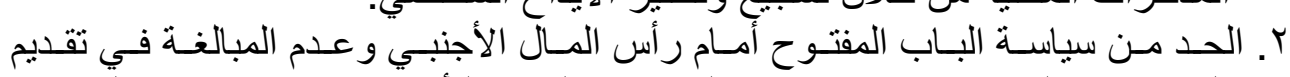

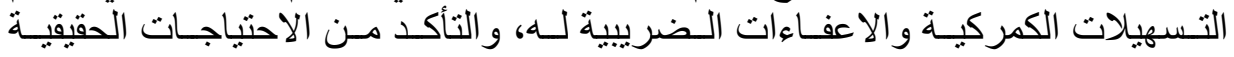

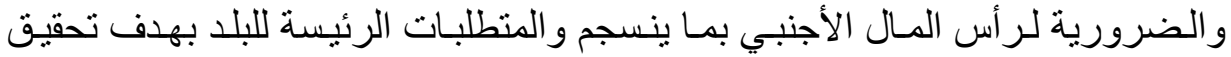

منفعة حقيقية.

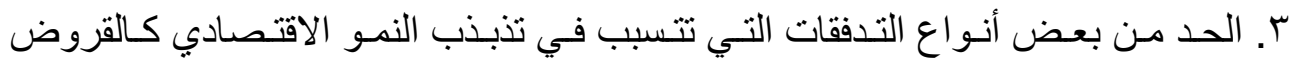

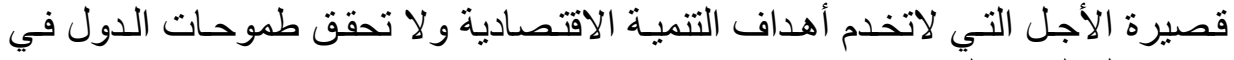
الاستغلال الرشيد للمواردها.

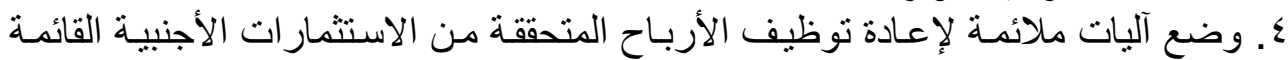

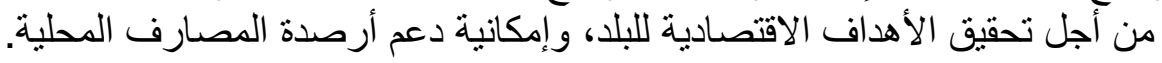

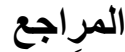

أولاً المراجع باللغة العربية

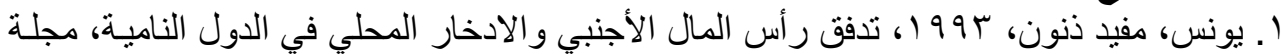

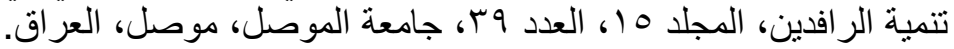

ثانياً المراجع باللغة الأجنبية

1. Asian Development Bank, 200`, Development Indicators Reference, Oxford,

2. Baharumshah, Ahmad Z. \& Thanoon, Marwan A., 2006, Foreign Capital Flow and Economic Growth in East Asian Countries, China Economic Review, Vol. 17.

3. Bailliu Jeannine N., 2000, Private Capital Flows, Financial Developing and Economic Growth in Developing Countries, Bank of Canada, Working Paper, 15, Ottawa, Canada.

4. Damodar N. Gujarati, 1995,Basic Econometrics, Third Edition, Mc Graw-Hill, London,UK.

5. Hachicha Nejib, 2003, Capital Inflow-National Saving Dynamic in Tunisia, Evidence Form Cointegratin Weak Exogeneity and Simultanous Error Correction Modeling, International Economic Journal, Vol. 17, No. 4 .

6. IMF, United Nations, Global Investment Report, 2007, Foreign Direct Investment and the Challenge of Development, Washington D.C., USA.

7. Kaminsky, G. \& Reinhart, C., 1998, Financial Crises in Asia and Latin America : Then and Now, American economic Review, Vol. 88, No. 2 .

8. Mishra Deepak \& Mody Ashoka \& Murshid Antu Panini, 2001, Private Capital Flows and Growth, IMF Working Paper, Vol. 38, No. 2 .

9. Prasad S. Eswar \& Rajan G. Raghuram \& Subramania Arvind, 2006, Foreign Capital and Economic Growth, Brookings Papers on Economic Activity, Vol. 8, No.1 . 
10. Soto Marcle and Reisen Helmut, 2002, The Need for Foreign Saving in Post Crisis Asia, Journal Asian Development Bank, Vol. 5, 65-84 . 